\title{
Projeto Ariranha: aplicação do gerenciamento de projetos visando à conservação da biodiversidade
}

\author{
Oldemar Carvalho Junior ${ }^{1}$ \\ Patricia P. Carioni Dutra ${ }^{2}$ \\ Volnete Alves ${ }^{3}$ \\ Paulo R. Ramos ${ }^{4}$
}

\section{RESUMO}

Apresenta-se aqui o relato de pesquisa da primeira fase do Projeto Ariranha, cujo principal objetivo é a instalação de uma base de pesquisa no Pantanal como apoio ao desenvolvimento do turismo de conservação de base comunitária, tendo a ariranha (Pteronura brasiliensis) como espécie bandeira. 0 planejamento e a execução do projeto envolvem a aplicação das boas práticas do PMBOK®. A metodologia para o estudo da ecologia da ariranha inclui o engajamento comunitário e a participação de ecovoluntários brasileiros e estrangeiros para a coleta de dados da biologia e do comportamento da espécie. 0 engajamento comunitário conta com a valorização da cultura e da divulgação dos produtos regionais, como também com o incentivo à implantação de unidades de pousadas familiares nas comunidades da região de pesquisa. A mobilização social como tema transversal tem como intuito criar a base comunitária de apoio ao projeto e, consequentemente, criar empatia positiva com a espécie alvo. A área de estudo é a região de Aquidauana, no bioma Pantanal do Mato Grosso do Sul. Até o presente foi criado um banco de dados estruturado em SIG do uso do solo para 10 $\mathrm{km}$ de cada margem do rio associado a um mapa temático. Foi definido um curso de capacitação em turismo de conservação de base comunitária e elaborada uma cartilha de educação ambiental a ser distribuída nas escolas da região. Considera-se que os alcances do projeto até o momento proporcionaram uma base para a execução da próxima fase destinada à pesquisa de campo.

Palavras-chave: Gerenciamento de projetos. Turismo de conservação. Base comunitária. Mobilização social. Pteronura brasiliensis.

\section{INTRODUÇÃO}

O objetivo principal deste trabalho é implementar uma proposta de pesquisa autossustentável de conservação da ariranha no Pantanal do Mato Grosso do Sul, com base no desenvolvimento do turismo de conservação de base comunitária com participação de ecovoluntários. O presente trabalho é desenvolvido no município de Aquidauana, no Mato Grosso do Sul.

1PhD em 0ceanografia Física. Gerente de Projetos do Instituto Ekko Brasil - ocjunior@ekkobrasil.org.br

${ }^{2}$ Graduada em Pedagogia - pcarioni@hotmail.com

${ }^{3}$ Especialista em Pedagogia - volnetealves@gmail.com

${ }^{4}$ Dr. em Engenharia de Produção. Professor na Faculdade de Tecnologia Senac Florianópolis - paulo@prof.sc.senac.br 
Ecovoluntário é o termo utilizado para definir um tipo especial de turista. Este representa um nicho de mercado em que projetos de pesquisa e/ou de conservação são oferecidos por agências internacionais de turismo, que trabalham em parceria com as organizações responsáveis por tais projetos. Um exemplo são os projetos de turismo de conservação do Instituto Ekko Brasil que são divulgados na Europa e Estados Unidos pelas melhores agências de turismo responsável, como a Cybelle Planète (Paris) e o Go Abroad (USA).

Apesar de bem conhecido no exterior, no Brasil, o tema é ainda novo e pouco divulgado. Em razão disso, pode-se afirmar que o turismo de conservação representa um novo nicho de mercado voltado para um público seleto (CARVALHO JUNIOR; SPERB, 2012; CARVALHO JUNIOR; SCHMIDT, 2004). Para que uma determinada atividade ou empreendimento seja considerada como turismo de conservação, ela precisa necessariamente ter um projeto de pesquisa integrado às ações de conservação e mobilização social, com participação de ecovoluntários. No presente caso, a ariranha foi selecionada como a espécie bandeira para a criação de um novo projeto de pesquisa com participação de ecovoluntários.

A ariranha é uma espécie considerada ameaçada pela Convention on International Trade in Endangered Species of Wild Fauna e Flora (CITES), da qual o Brasil é signatário, pela U. S. Endangered Species Act (USESA), e também pela International Union for Conservation of Nature (IUCN). No Brasil, a espécie apresentava ampla distribuição, desde o Rio Grande do Sul até a Amazônia, com exceção da região semiárida da caatinga, estando presente nos Biomas Amazônia, Pantanal, Cerrado e Mata Atlântica (REIS et al., 2006). Atualmente, acredita-se que a espécie esteja extinta em Minas Gerais, Rio de Janeiro, Santa Catarina e Rio Grande do Sul. Logo, seu status de conservação é crítico e deve ser abordado de forma transparente, por meio da educação e mobilização social, a fim de que a situação possa ser revertida.

O tema transversal abordado na presente proposta é a educação e mobilização social para maior sensibilização e participação das comunidades do município de Aquidauana. As ações propostas baseiam-se no desenvolvimento do empreendedorismo ético (DOLABELA, 2008a, 2008b). Esse tipo de empreendedorismo deve gerar valores positivos para as comunidades, incluindo os aspectos ambientais, além dos econômicos e sociais. Um exemplo é o turismo de conservação que representa uma atividade inovadora no Brasil.

Segundo Arendt (1981), a responsabilidade civil sobre a vida social depende da mobilização. No caso da ariranha, a mobilização pode ser uma solução para a conservação da espécie. 0 valor positivo do Projeto sobre a comunidade é almejado por meio do crescimento econômico e desenvolvimento social que o turismo de conservação pode trazer. Dessa forma, a ariranha passa a ser vista como um ser que vale a pena ser preservado, fazendo parte de um ativo, que possui valor econômico e social.

Assim, o conhecimento produzido é utilizado para a modificação de uma realidade adversa, com o envolvimento ativo dos pesquisadores por meio do apoio técnico institucional. Tal abordagem não é novidade e faz parte do princípio da pesquisa-ação, como estratégia de pesquisa (COUGHLAN; COGHLAN, 2002; MELLO et al., 2012). Nada garante, porém, que a estratégia dará resultado positivo; mas, como bem salienta Coughlan e Coghlan (2002), as dificuldades encontradas durante o processo da pesquisa-ação devem ser discutidas, servindo como contribuição à pesquisa realizada. Dentro desse contexto, o turismo de conservação também se apresenta como ferramenta de ação social.

O turismo de conservação implica a participação ativa do turista em ações voltadas para a conservação da biodiversidade. Dentro de um projeto de pesquisa, o turismo de conservação pode ser visto como um tema transversal, podendo, inclusive, representar uma ferramenta de mobilização social. Em setembro de 2012, em diferentes datas, buscas no site Google Brasil com a expressão turismo de conservação resultaram em zero ocorrências de retorno, tanto para páginas como para títulos da internet. A exceção foi para os trabalhos publicados pelo próprio Instituto Ekko Brasil e/ou por seus pesquisadores. A maior parte dos resultados associaram o turismo em Unidades de Conservação, mas não exatamente o turismo de conservação.

O conceito de turismo de conservação ainda não é bem definido, sendo pouco conhecido no Brasil, podendo muitas vezes ser confundido como ecoturismo ou turismo de aventura. No caso do turismo de conservação, o turista tem participação ativa em um projeto de pesquisa, e/ou conservacionista, voltado para a conservação da biodiversidade. Em virtude disso, o termo turismo científico também pode ser aplicado. Entretanto, como o termo turismo científico pode ser muito restritivo quanto ao público-alvo, o turismo de conservação pode representar a escolha mais apropriada do ponto de vista econômico e social, além do ambiental, voltado para a sustentabilidade do projeto (CARVALHO JUNIOR; SCHMIDT, 2004).

A preocupação com a definição do conceito procede a partir do momento em que o turismo de conservação pode representar uma alternativa econômica importante em Unidades de Conservação, em especial em Âreas de Proteção Ambiental (APAs) (HOEFFEL et al., 2008). Contudo, o enfoque meramente econômico traz consigo o risco de que o discurso do turismo de conservação caia no mesmo sentido reducionista do "sustentável". Independentemente disso, é importante que se tenha em mente que o 
potencial do turismo como estimulador de rede social, aproximando diferentes culturas e povos, não deve ser negligenciado, principalmente se puder ser aplicado para modificar realidades adversas ou impeditivas à melhoria de qualidade de vida.

A banalização do termo "turismo sustentável" vem do fato de que as propostas podem se encaixar dentro de uma escala que vai do zero ao infinito, fruto de diferentes interesses, visões e experiências a respeito do uso dos recursos naturais (LEFF, 2002). Numa tentativa de estreitar a discussão sobre o tema, pode-se lançar mão de outros conceitos, como turismo científico (CARVALHO JUNIOR; SCHMIDT, 2004) e turismo de base comunitária e biodiversidade. Portanto, turismo de conservação de base comunitária e/ou para a conservação da biodiversidade é outro termo que pode ser aplicado, de forma melhor contextualizar, tanto na mídia quanto no meio acadêmico, o que de fato vem a ser o turismo de conservação.

Independentemente de qualquer discussão ou polêmica que se refiram à definição de turismo de conservação, toda atividade que almeja ser enquadrada como tal deve atender a requisitos mínimos que a caracterizem. Ou seja, deve estar associada a um projeto de conservação, envolver a comunidade como personagem principal e aplicar técnicas de educação ambiental voltadas à mobilização social. 0 principal objetivo do turismo de conservação deve ser o de estimular a participação de uma gama maior das diferentes partes, facilitando a resolução de situações conflitivas, modificando realidades adversas e melhorando a qualidade de vida.

Um processo de mobilização representa convocação de vontades que, por sua vez, é feita por intermédio de ações de comunicação (TORO; WERNECK, 2004). O projeto de comunicação para mobilização social inclui a coletivização dos objetivos, ou seja, a causa pela conservação da ariranha passa a ser coletiva. As ações sociais são baseadas essencialmente no processo educativo e no formativo, objetivando criar vantagens ecológicas e econômicas para gerar renda. Nesse sentido, a mensagem a ser transmitida à sociedade é a de que a inclusão social do indivíduo passa pela conquista da sustentabilidade, da preservação da cultura local e da manutenção dos subsistemas.

Portanto, a conservação da ariranha busca colocar a vida como centralidade ética, ecológica e educativa. Não se trata apenas de definir regras e ferramentas de ação de pesquisa e conservação, mas também de desenvolver aspectos relacionados à cultura, aos conhecimentos e aos sentimentos, de forma a desenvolver um processo afetivo em direção ao projeto em foco e a espécie considerada. Esse tipo de abordagem faz por exigir a aplicação de novas técnicas de gerenciamento de modo a aumentar as chances de sucesso do projeto.

Para tanto, a implementação do Projeto Ariranha passa pela aplicação das técnicas e ferramentas de gerenciamento de projetos abordados pelo Guia PMBOK ${ }^{\circledR}$ (Project Management Book of Knowledge), de modo a determinar para o projeto as etapas de planejamento, os planos de gerenciamento para controle e monitoramento das ações, e definir as etapas de execução na área de estudo.

0 conjunto dos planos de gerenciamento, além de apropriados, revela-se de grande utilidade para organizações do Terceiro Setor, as Organizações Não Governamentais (ONG). Nos últimos anos, as ONGs no Brasil evoluíram de forma dramática, mas muitas vezes sem uma regulação eficiente. Exemplo disso são os escândalos de ONGs fantasmas ou criadas apenas com o intuito de receberem dinheiro de políticos e empresários para uso indevido, prejudicando o trabalho das ONGs sérias e honestas. Uma forma de caracterizar a seriedade é pelas Organizações da Sociedade Civil de Interesse Público (OSCIP).

As OSCIP representam as ONGs com qualificação, reguladas pela Lei no 9.790, de 23 de março de 1999 (BRASIL, 1999). 0 título é fornecido pelo Ministério da Justiça do Brasil e possibilita a criação de parcerias com o Poder Público. A principal vantagem dessa parceria para o Poder Público é a de dividir as responsabilidades do encargo administrativo e da administração de contas. A renovação da qualificação OSCIP se dá anualmente e, para tanto, a Instituição precisa comprovar total transparência na contabilidade, no uso e na gestão dos recursos. Antes do pedido de renovação, as contas da Instituição precisam passar pelo Tribunal de Contas do Estado, para então serem encaminhadas ao Ministério da Justiça.

Parcerias, potencializadas por meio das boas práticas do PMBOK®, têm a vantagem de abrir outras possibilidades e alternativas sustentáveis para o Terceiro Setor. Ser uma ONG autossustentável no Brasil não é tarefa fácil, e isso passa pela profissionalização e melhoria da qualidade dos recursos humanos. Ter o controle dos processos envolvidos é fundamental para que isso ocorra. Por exemplo, o gerenciamento de projetos como este, da Ariranha, torna o projeto mais confiável para potenciais patrocinadores e/ou doadores, que podem abater o montante no imposto de renda. Organizações, como o Instituto Ekko Brasil (IEB), que funcionam por projetos, podem se beneficiar de um gerenciamento mais eficiente, traduzindose em sustentabilidade em longo prazo. 0 turismo de conservação, por exemplo, visto como uma forma de mobilização social e não apenas como um empreendimento, pode garantir resultados em médio e longo prazo, com benefícios ambientais, sociais e econômicos para a comunidade.

Assim sendo, o gerenciamento de projetos aplicados ao Terceiro Setor pode ser de considerável 
importância para a sustentabilidade e continuidade de programas com objetivos sociais, econômicos e ambientais. A maior eficiência associada à agilidade na gestão dos recursos pode trazer benefícios importantes à sociedade. Os riscos são menores, assim como os custos. 0 gerenciamento por meio das boas práticas do $\mathrm{PMBOK}^{\circledR}$ representa importante aliado no desenvolvimento de projetos por ONGs.

\section{2 ÁREA DE ESTUDO}

Aquidauana apresenta uma população de cerca de 45.000 habitantes, equivalente a uma densidade de 2.65 hab./km2, para uma área de $16.958 .496 \mathrm{~km}^{2}, 4.75 \%$ do Estado (IBGE, 2010). A Figura 1 mostra a área urbana de Aquidauana e parte do rio, de mesmo nome, imagem do Satélite Sino-Brasileiro de Recursos Terrestres (CBERS), de 30 de julho de 2008, cortesia do Instituto Nacional de Pesquisas Espaciais (INPE).

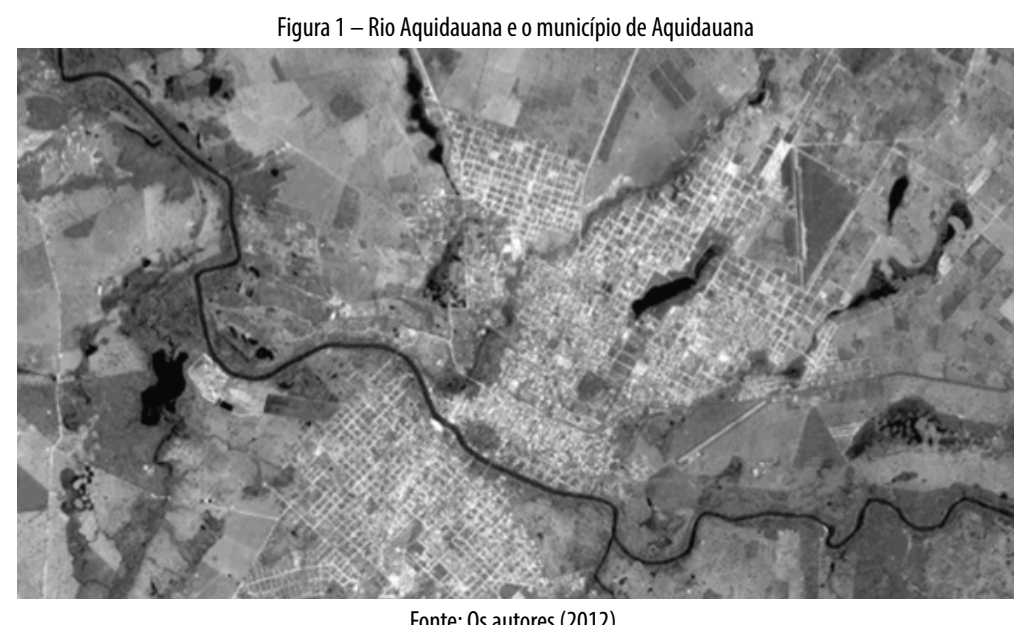

As principais atividades do município estão relacionadas à industria, serviços e agropecuária. Cerca de 10 mil ha são utilizados para o cultivo do milho, mandioca e olerícolas, a pecuária ocupa uma área de quase 1 milhão de ha de pastagem natural onde são criados 811 mil cabeças de bois. O Produto Interno Bruto (PIB) de Aquidauana é de R \$398.906,580, resultando em um PIB per capita de R 8.622,02 (IBGE, 2010) e um Índice de Desenvolvimento Humano (IDH) médio de 0,757 (PNUD, 2011).

Apenas como exemplo, é possível comparar os dados anteriores com o município de Indaial/SC, que possui um tamanho populacional similar, de 47.612 habitantes, mas uma densidade muito maior, de 110 hab./km2, resultante de uma área bem menor, de $431 \mathrm{~km} 2$. O PIB e o IDH de Indaial são, entretanto, muito superiores, de $\mathrm{R} \$ 20.170,32$ e 0,825, respectivamente. Tais diferenças podem ser, em parte, explicadas pela maior diversificação econômica, incluindo o turismo regional, cujo foco é a Oktoberfest da cidade vizinha Blumenau/SC. Assim como o rio Itajaí representa um importante recurso natural para o desenvolvimento do turismo (CARVALHO JUNIOR; RODRIGUES; SCOTON, 2009), o rio Aquidauana pode servir como uma alavanca para a melhoria da qualidade de vida das comunidades, principalmente as ribeirinhas. A água, neste particular, assume um caráter preponderante para o desenvolvimento do turismo.

A formação de aglomerados urbanos e agropastoris ao longo do rio Aquidauana e seus tributários trazem como consequência a crescente necessidade de água para abastecimento doméstico e agrícola, e para irrigação e lazer. Atualmente, a quase totalidade das atividades humanas observadas na área de estudo faz por exigir, cada vez mais, maior disponibilidade das águas continentais. Entretanto, o que se observa na área de estudo é o lançamento de efluentes domésticos e industriais, diretamente nos corpos d'água. Tal situação acaba por reduzir ainda mais a possibilidade de utilização dos recursos hídricos para o turismo.

A vegetação original do rio é, em sua maior parte, composta por densa floresta pluvial tropical. 0 processo histórico de ocupação na área de estudo baseia-se na utilização de grandes extensões de áreas, tanto de encostas quanto de planícies, para o desenvolvimento das atividades agropastoris. Com isso, o recobrimento de mata nativa, com o passar dos anos, foi reduzindo-se drasticamente.

Considerando a situação atual e a presente proposta de projeto, evidencia-se que o sucesso passa por mudanças de atitudes e comportamentos. Para tanto, o projeto de comunicação para mobilização social 
inclui a coletivização dos objetivos, como, por exemplo, a causa pela revitalização da área ribeirinha que impacta diretamente na conservação da ariranha. As características da espécie a tornam uma excelente bandeira para a coletivização de objetivos em prol da conservação dos recursos aquáticos.

A ariranha (Pteronura brasiliensis) é um mamífero carnívoro, semiaquático, da Família Mustelidae, Subfamília Lutrinae e Genero Pteronura. É o maior mustelídeo conhecido, podendo atingir 1,80m de comprimento e $65 \mathrm{~cm}$ de cauda. 0 peso varia de 26 a $32 \mathrm{~kg}$ nos machos e de 22 a $26 \mathrm{~kg}$ nas fêmeas (DUPLAIX, 1980). A cabeça é larga e achatada, os olhos grandes e as orelhas são pequenas e redondas. As patas possuem garras e membranas interdigitais, e a cauda é longa, musculosa e dorso-ventralmente achatada (EISENBERG; REDFORD, 1999). Essas características fazem da espécie um predador altamente eficiente e ágil dentro da água.

A ariranha era comum em praticamente todos os rios tropicais e subtropicais brasileiros. Atualmente a presença da espécie restringe-se a áreas isoladas do Brasil, Peru e Guianas (GROENENDIJK et al., 2005). No Brasil, o rio Aquidauana destaca-se como a região onde populações de ariranhas podem ser mais facilmente observadas e estudadas no ambiente selvagem. Por exemplo, Tomás et al. (2000) observaram um total de noventa indivíduos num trabalho realizado nos rios Aquidauana e Miranda.

O Rio Aquidauana, em sua maior parte, é um ambiente de águas calmas, sem muitas corredeiras, o que favorece a uma alta produtividade e, consequentemente, maior concentração de peixes (CARTER; ROSAS, 2007; EMMONS; FEER, 1999; REIS et al. 2006); isso explica o grande número de ariranhas no local. Segundo Chiarello et al. (2008), o Pantanal abriga as maiores populações. Por outro lado, no restante do Brasil, as populações são pequenas, algumas isoladas e em declínio. A espécie é bastante social, se comparada com a lontra, vivendo em grupos familiares de cinco a quinze indivíduos. Além disso, o fato de serem diurnas e barulhentas facilita o estudo e a visualização, o que contribui para a participação de ecovoluntários. Os indivíduos podem ser identificados porque possuem manchas brancas na pelagem preta do pescoço, que funcionam como impressão digital.

Comparado com pesquisas sobre a lontra neotropical, o trabalho de campo com ariranhas é mais fácil em razão do comportamento diurno e pelo fato de estarem organizadas na forma de grupos. A ariranha é considerada como sendo territorialista, fazendo uso de vocalizações, latrinas e marcações odoríferas para delimitar o território do grupo (PEREIRA, 2004; CARTER; ROSAS, 2007). Segundo Carter e Rosas (2007), o tamanho do território pode variar de 12 a $32 \mathrm{~km}$ em rios. A espécie constrói as próprias tocas nas margens dos rios, sob raízes ou sob árvores caídas. As tocas são comunitárias e usadas normalmente para descanso e criação dos filhotes (GROENENDIJK et al., 2005). A gestação dura de 52 a 70 dias, nascendo de um a cinco filhotes, que saem da toca com cerca de duas a três semanas de vida (CARTER; ROSAS, 2007; CHIARELLO et al., 2008).

As características ecológicas e comportamentais da ariranha fazem com que ela seja uma espécie ideal para pesquisas envolvendo a participação de ecovoluntários. Isso permite e facilita o trabalho de mobilização social nas comunidades do entorno. Não só a ariranha beneficia-se com isso, mas toda a biodiversidade da região. Por intermédio do trabalho com a ariranha, a mobilização acaba por criar uma nova consciência conservacionista na comunidade.

\section{METODOLOGIA}

A presente metodologia baseia-se na pesquisa qualitativa com objetivo de aprimorar os processos de pesquisa nas etapas posteriores do projeto. 0 projeto inicia com o levantamento de informações da área de estudo para então definir os objetivos específicos. Para tanto, a pesquisa-ação é empregada (CRAIGHEAD; MEREDITH, 2008), auxiliando e fundamentando possíveis mudanças futuras no escopo do projeto.

0 projeto tem uma relação muito forte com a mobilização social, quando os principais problemas que afetam a ariranha devem ser identificados. Tendo como base tal informação, uma dada realidade pode ser modificada mediante estratégias bem definidas e específicas aos problemas listados. Esse tipo de abordagem vem ao encontro do que preconiza o método da pesquisa-ação (COUGHLAN; COGHLAN, 2002; MELLO et al., 2012). Outro fato que caracteriza a pesquisa-ação é o envolvimento ativo dos pesquisadores com o objeto da pesquisa (COUGHLAN; COGHLAN, 2002; THIOLLENT, 2007), realizada dentro da organização (Instituto Ekko Brasil), como é o presente caso. Esse envolvimento dos pesquisadores faz por exigir um plano de comunicação eficiente e interativo entre os atores-pesquisadores. A comunicação foi prevista desde a concepção do projeto, refletindo-se nas ferramentas selecionadas.

Várias ferramentas informatizadas foram testadas e utilizadas para a construção do projeto, entre elas o Open Project, o WBS Tool, o Dropbox, o FreeMind, o GVSIG e o XMind. 0 software Open Project representou a 
principal ferramenta de gestão do projeto. Foi utilizado principalmente para organizar as tarefas no Gráfico de Gantt, definir o caminho crítico, os recursos e os custos (BENIZ; ORIDES JÚNIOR; KATO, 2008). Para definir a EAP, organograma e hierarquias do projeto, optou-se pelo WBS Tool pela praticidade e desenho gráfico. Os dados foram organizados em planilhas eletrônicas do Numbers e Excel, principalmente para criação do Fluxo de Caixa do projeto. Por meio do Fluxo de Caixa, foram realizados o controle e o monitoramento financeiro.

O Dropbox foi importante para o compartilhamento dos arquivos com o restante da equipe. 0 projeto era disponibilizado para toda a equipe a qualquer momento. As contribuições eram feitas e registradas usando cores para controle de mudanças.

Reuniões semanais presenciais com os autores e reuniões bimensais com o staff do IEB também foram essenciais para discutir o andamento dos trabalhos e receber um feedback técnico. Tais reuniões foram importantes para tirar dúvidas e manter o rumo dos trabalhos dentro da filosofia e estratégia do Instituto. Igualmente importantes foram as pesquisas bibliográficas em livros referências PMBOK® e em outros trabalhos aplicando as boas práticas. Além disso, imagens satélites da área de estudo foram obtidas diretamente do Instituto Nacional de Pesquisas Espaciais (INPE), de São José dos Campos. Essas imagens foram imprescindíveis para uma análise preliminar da região, em especial do rio Aquidauana e da zona de Área de Preservação Permanente (APP) ao longo do rio.

Dados socioeconômicos sobre o município foram obtidos do site do Instituto Brasileiro de Geografia e Estatística (IBGE) e do Programa das Nações Unidas para o Desenvolvimento (PNUD) e informações educacionais, do site do Índice de Desenvolvimento de Educação Básica (IDEB). Análises do Índice de Desenvolvimento Humano (IDH) e outros indicadores financeiros sobre o Brasil foram acessados no banco de dados do World Bank. A digitação foi feita por meio de dois processadores de texto: Word e Pages, ambos em Mac OSX 10.7.5. Planilhas em Excel foram organizadas para análise de investimento baseado em indicadores financeiros, como Valor Presente Líquido (VPL), Valor Presente Líquido Anualizado (VPLa), Taxa Interna de Retorno (TIR), Retorno sobre o Investimento (ROI) e PAYBACK (tempo de retorno do investimento), com o fim de definir a viabilidade financeira do projeto.

Todos os documentos foram arquivados durante o desenvolvimento dos trabalhos em uma pasta pública, compartilhada, mas de acesso restrito ao staff do Instituto e da equipe do projeto. Ao final dos trabalhos de planejamento, foi feito o encerramento dessa etapa do projeto com uma apresentação oral dos principais resultados obtidos para o staff do IEB. Os documentos gerados pelo projeto foram arquivados em uma pasta pública, compartilhada aos técnicos do Instituto. Cópia do projeto final foi encaminhada ao patrocinador, Petrobras/Programa Petrobras Ambiental.

A seleção da base de operações do projeto aconteceu por intermédio de uma viagem de reconhecimento de uma semana durante o mês de março de 2013. Nesse mesmo período, foram realizadas duas expedições de reconhecimento do rio Aquidauana para a definição da área de amostragem. Com o início do funcionamento da base e da contratação do coordenador local, começaram-se aos trabalhos de mobilização social, que consistiram em reuniões com as principais lideranças políticas e públicas, além da apresentação do projeto na Secretaria Municipal de Educação. Com isso, a base passou a receber visitas de escolas e grupos organizados das cidades de Aquidauana e Anastácio. Por ocasião das visitas, palestras eram feitas e vídeo institucional do projeto era apresentado.

0 projeto também passou a participar de eventos ambientais e participar do Fórum de Turismo do Pantanal e Conselho Municipal de Turismo (COMTUR). Entre outros movimentos, cabe ressaltar o convite para participar da Conferência Municipal de Meio Ambiente de Anastácio e da discussão da Política Nacional de Gestão de Resíduos Sólidos.

Essa etapa de mobilização foi planejada e executada durante o ano de 2013. Durante 2014, três projetos de pesquisa estarão também sendo desenvolvidos: o levantamento de grupos de ariranhas nos rios Aquidauana e Miranda; a definição da percepção dos índios Terenas com relação à ariranha; e a definição de uma trilha aquática no rio Aquidauana, num trecho pertencente aos municípios de Aquidauana e Anastácio.

\section{GERENCIAMENTO DO PROJETO}

O Gerenciamento do Projeto foi realizado por meio de nove Planos: Integração, Escopo, Tempo, Custo, Qualidade, Recursos Humanos, Comunicações, Riscos e Aquisições. A seguir são feitos comentários a respeito dos planos de gerenciamento de cada uma dessas áreas que foram desenvolvidas para o presente projeto.

0 termo de abertura do projeto (TAP) foi o documento que oficializou o projeto com o patrocinador. Foi parte da iniciação, juntamente com a análise do ambiente do projeto.

0 plano de gerenciamento da integração do projeto foi responsável por unir e interligar todos 
os processos e atividades que envolveram o projeto. Portanto, o gerenciamento da integração do projeto, durante a realização da primeira fase, representou uma ação integradora de processos que envolveram a iniciação, o planejamento, a execução, o monitoramento e controle, realizando o controle integrado das mudanças, e, por fim, o encerramento da fase.

O planejamento representou o conjunto de regras para executar o projeto, agregando os resultados obtidos com os demais processos que fizeram parte do gerenciamento da integração. Dessa forma, o planejamento é importante, pois prepara, integra e coordena todas as ações que fazem parte do plano do projeto, assim como, dos planos de gerenciamento do projeto.

A execução passou pela realização das atividades definidas no plano do projeto com o objetivo de cumprir o estabelecido no escopo. 0 monitoramento e controle dos processos foram importantes durante todo o trabalho, para atingir os objetivos, passando pela iniciação, planejamento, execução e encerramento da fase.

O controle integrado de mudanças fez parte do Gerenciamento de Integração do projeto. Teve como objetivo principal controlar as necessidades e pedidos de mudanças, ao mesmo tempo garantindo que tais mudanças fossem benéficas ao projeto. Esse processo foi realizado durante todo o desenvolvimento da primeira fase do projeto, desde a iniciação até o encerramento.

O encerramento administrativo da fase representou a aceitação formal da sua execução pelo IEB e pelo patrocinador. Teve por preocupação disseminar as informações obtidas entre os principais stakeholders. Incluiu avaliações do projeto e organização das lições aprendidas, de forma a estarem disponíveis para futuros projetos. 0 encerramento da fase incluiu: designação de pessoal e recursos materiais, obrigações contratuais, avaliação do atendimento às necessidades dos stakeholders e entrega dos produtos.

0 plano de gerenciamento do escopo foi o que coordenou o plano, descrevendo os principais processos do projeto. Também definiu as fases mais importantes, assim como as devidas entregas. A criação, revisões do plano, aprovações e eventuais alterações foram sempre atualizadas no escopo, gerando uma nova linha de base.

Para atingir os objetivos específicos planejados, foi definida uma sequência de atividades interligadas. Para cada tarefa, foi estimado o tempo de execução necessário. Para o gerenciamento do tempo, foi utilizado o software Open Project; de forma a estimar a duração das atividades, foram utilizadas principalmente a estimativa análoga e a opinião especializada do gerente do projeto. Também foram levadas em conta informações acerca da área de estudo.

Os gastos, assim como as atividades, foram organizados por trimestre, ao longo de doze meses, coincidindo com a liberação das verbas pelo patrocinador, a qual ocorreu de três em três meses. Portanto, o gerenciamento de custos está diretamente ligado ao fluxo de caixa do projeto, sendo os desembolsos realizados trimestralmente, totalizando quatro trimestres na primeira fase.

0 plano de gerenciamento da qualidade concentrou as informações referentes à garantia da qualidade dos produtos e processos do projeto. Este também define as atividades e seus responsáveis. 0 objetivo foi assegurar os procedimentos acordados com os stakeholders, em conformidade com os requisitos do escopo.

Os processos de controle de qualidade respeitaram as seguintes premissas: a garantia da qualidade foi realizada com base nos indicadores de qualidade do projeto. A cada inspeção, os indicadores foram verificados, e a análise foi incluída nos relatórios trimestrais correspondentes; o controle de qualidade foi feito com base nos requisitos e padrões de qualidade das entregas definidos no plano de gerenciamento da qualidade.

0 plano de gerenciamento de recursos humanos descreve os processos que organizam e gerenciam a equipe do projeto. Para uma melhor compreensão desse gerenciamento, um mapa mental dos Recursos Humanos foi produzido, organizando entradas, ferramentas, técnicas e saídas para a execução do trabalho. No organograma do projeto, foram distribuídos, de forma hierárquica, os principais stakeholders envolvidos na pesquisa. A avaliação dos resultados do projeto implica diretamente a avaliação de desempenho de cada membro da equipe. A capacitação e aperfeiçoamento da equipe foi feita por cursos de capacitação, workshops internos e estímulos a cursos de pós-graduação.

A estratégia de comunicação tem por objetivo comunicar de forma clara e compreensiva o valor do projeto, ou seja, o que o projeto, por meio de suas atividades, produtos e serviços, tem para oferecer ao público-alvo (stakeholders). Além disso, essa estratégia deve tornar transparente o posicionamento da empresa patrocinadora, considerando, para tanto, a identidade do Instituto Ekko Brasil; a imagem que o Instituto e o Projeto Ariranha tem perante a sociedade; e a proposta de ação por meio do projeto, materializada por intermédio de seus produtos e serviços.

No que se refere à comunicação interna do projeto, ocorreu por meio de reuniões semanais (informais) 
e mensais (formais) com toda a equipe. Apresentações orais semanais e relatórios técnicos mensais foram utilizados para manter a equipe bem informada a respeito do andamento do trabalho e para corrigir qualquer desvio dos objetivos ou dificuldades de operação. Duas ferramentas principais foram utilizadas para comunicação a distância: o Dropbox (arquivo de documentos) e Skype para contatos on-line.

0 plano de gerenciamento dos riscos coordenou a identificação dos riscos externos, técnicos, organizacionais e gerencial. 0 Plano definiu as condições para a análise qualitativa dos riscos, que consiste na probabilidade dos riscos e dos impactos para os objetivos do projeto. A identificação, a avaliação e o monitoramento de novos riscos foram comunicados em reuniões, respeitando as seguintes categorias para as suas devidas respostas: prevenção (eliminação), aceitação passiva, aceitação ativa (contingenciamento), mitigação, transferência (seguro), exploração (aumento da probabilidade), compartilhamento (parcerias) e melhora (aumento do impacto positivo).

0 plano de gerenciamento das aquisições organizou o processo de planejamento da aquisição, definiu o que deveria ser adquirido para a execução do projeto de forma a atender aos requisitos do escopo. Para as aquisições, foi utilizado um formulário de declaração de trabalho (SOW), próprio do IEB. Nesse formulário, constaram critérios para a aquisição de cada produto ou serviço, bem como para a escolha dos fornecedores. A seleção de fornecedores, serviços e materiais foi feita com o auxílio da internet, reuniões presenciais e opinião especializada. A administração dos contratos serviu para gerenciar o relacionamento com o fornecedor. $\mathrm{O}$ aceite do produto foi feito mediante conferência com o especificado no modelo de trabalho (SOW).

\section{RESULTADOS PRELIMINARES}

A fim de facilitar o trabalho de seleção das informações relevantes, foi utilizado o conceito de Públicos Relevantes, isto é, pessoas e organizações com as quais o Instituto Ekko Brasil mantém relacionamentos para cumprir a Missão. A Figura 2 apresenta os principais Públicos Relevantes externos.

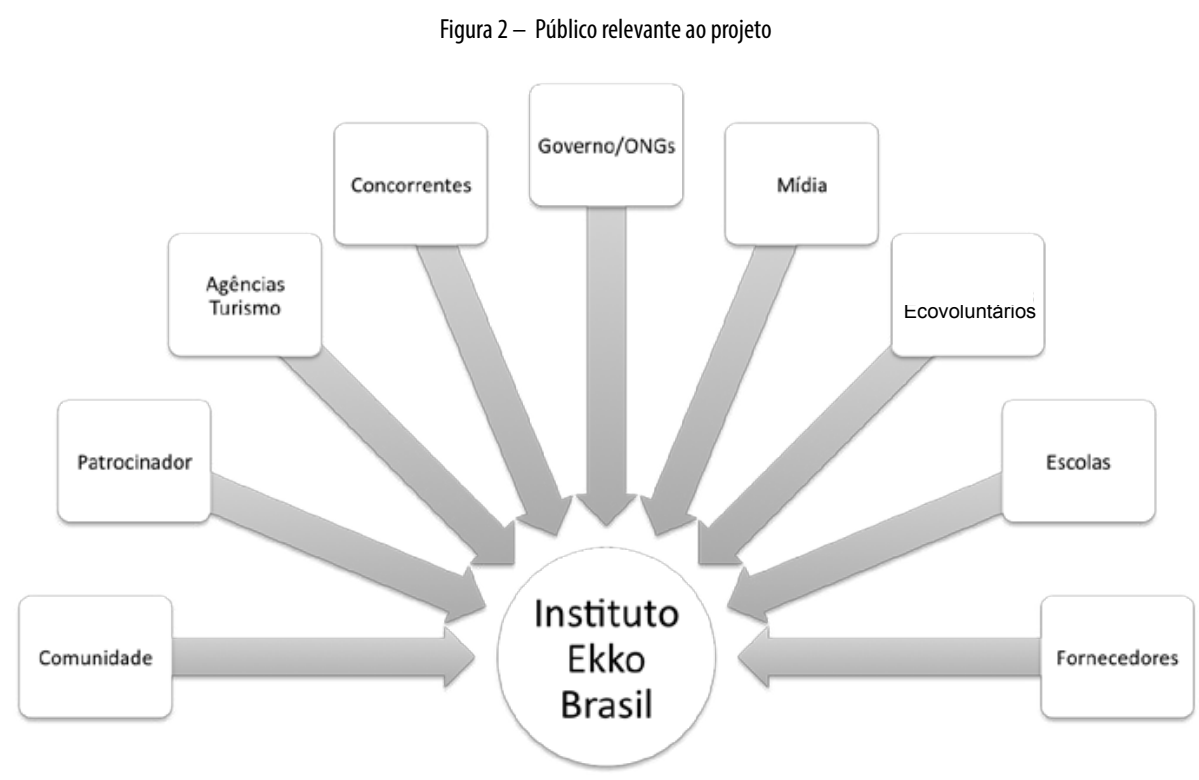

Fonte: Os autores (2012

A análise do ambiente onde o projeto se insere é fundamental para a definição do planejamento estratégico. 0 ambiente externo representa oportunidades e ameaças ao projeto. As oportunidades favorecem e interagem com o IEB. Exemplo é a implantação da nova base de operações no Pantanal, expandindo a área de ação da organização e resultando num provável crescimento de usuários/ecovoluntários. Ameaças são prejuízos ao projeto, podendo levar à sua extinção. A Figura 3 apresenta uma análise do ambiente do projeto. 
Figura 3 - Análise do Ambiente do projeto

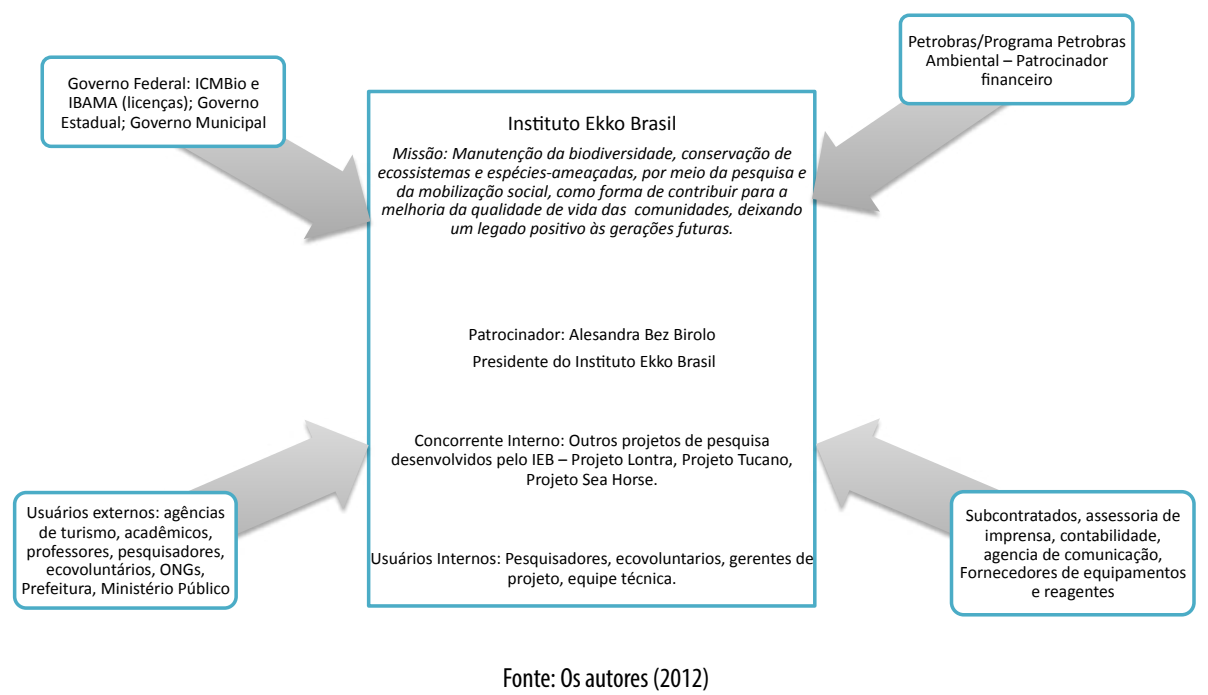

A análise do ambiente do projeto revela a miríade de autores com que o IEB se relaciona em níveis diferentes de complexidade. Quatro grupos principais podem ser observados: (1) o patrocinador financeiro; (2) o poder público (federal, estadual e municipal); (3) os usuários externos (agências de turismo, acadêmicos, professores, pesquisadores, ecovoluntários, ONGs, Prefeituras e Ministério Público); e (4) subcontratados, assessoria de imprensa, contabilidade, agência de comunicação e fornecedores de equipamentos e reagentes. A parte interna da Figura 3 apresenta a missão do IEB, o patrocinador, o principal concorrente interno e os usuários internos.

0 ambiente do projeto contextualiza os aspectos sociais, culturais, econômicos, ambientais, internacional e político com que a equipe deve lidar. Essa visão holística é importante para o planejamento e implementação do projeto. Não só o gerente do projeto mas toda a equipe têm uma visão geral dos principais relacionamentos com os diferentes stakeholders.

O Planejamento do Projeto buscou quantificar o tempo e orçamento, facilitando o acompanhamento do projeto e da equipe pelo gerente. Os detalhamentos foram definidos dentro do Plano do Projeto que representou a referência básica para a sua execução e teve como base o Escopo do Projeto (MOURA; BARBOSA, 2006). O Plano de Projeto foi estruturado com base em dezenove componentes básicos: escopo, fases, produtos, premissas, riscos e respostas planejadas, recursos-chave, restrições, projetos inter-relacionados, requisitos e especificações contratuais, critérios de aceitação, assinaturas e aprovações, revisões formais, custos, análise de viabilidade econômico/financeira, tarefas programadas, matriz de responsabilidade, cronograma, principais marcos, indicadores de desempenho e metas.

O escopo foi desenvolvido para gerar os produtos do projeto, incluindo a instalação de uma base de pesquisa de apoio aos pesquisadores, o desenvolvimento de trabalhos de pesquisa com a ariranha no rio Aquidauana, ações de mobilização social no município de Aquidauana e ações de educação ambiental nas escolas municipais.

As principais fases do projeto incluíram o planejamento e gerenciamento do projeto em Santa Catarina; a implantação da base de pesquisa em Aquidauana; o desenvolvimento da Pesquisa no rio Aquidauana; a mobilização social; os relatórios trimestrais; e o fechamento.

Os principais produtos a serem gerados pelo projeto são: plano de gerenciamento do projeto elaborado; base de pesquisa instalada; banco de dados estruturado em SIG; mapas temáticos ambientais e socioeconômicos disponíveis on-line e impressos; protocolo de atendimento aos ecovoluntários definido; pelo menos uma pousada familiar cadastrada e apta a receber ecovoluntários; cartilha de educação ambiental pronta para distribuição nas escolas; e curso de capacitação em turismo de conservação executado.

A análise de viabilidade econômico-financeira do presente projeto é feita sob critérios que incluem a capacidade técnica e experiência da equipe, assim como da competência administrativa da patrocinada. A sustentabilidade, em longo prazo, do projeto em foco é o objetivo principal da organização. De forma a atingir esse objetivo, é fundamental a qualidade dos produtos criados, assim como da oferta de preços competitivos relacionados ao turismo de conservação. 
Controle de custos, qualidade e eficiência operacional representam aspectos fundamentais na sustentabilidade em longo prazo de organizações não governamentais. A autossustentabilidade do projeto é almejada, principalmente, com a participação de ecovoluntários e com a venda de produtos, como camisetas, bonés e joias de prata. Os produtos serão vendidos na lojinha do Centro de Visitação do IEB em Florianópolis e na Base de Pesquisa em Aquidauana. Para tanto, o projeto será anunciado nas principais agências de turismo sustentável da Europa e USA.

Apesar de ser uma ONG, sem finalidade econômica, o Instituto Ekko Brasil necessita ser autossustentável para poder sobreviver num ambiente de alta competitividade. A sustentabilidade do Instituto é obtida, principalmente, por intermédio de projetos. Para tanto, a análise de investimento é de fundamental importância na tomada de decisões. Isso não é muito diferente do que estabelece Brito (2006), quando afirma que projetos de investimento necessitam ser rentáveis, sejam públicos ou privados.

Segundo Lapponi (2007), projetos podem ser caracterizados como substituição, modernização, expansão, lançamento de produto, estratégico, obrigatório, intangível e financeiro. No caso do Projeto Ariranha, pode ser considerado com um projeto estratégico por representar uma nova área de trabalho para o IEB. Por outro lado, considerando o patrocinador (Petrobras/Programa Petrobras Ambiental), o mesmo projeto pode ser caracterizado como intangível. No caso, o patrocinador não busca retorno financeiro, mas sim, associar a imagem a um projeto de conservação com viés social. Independentemente disso, a empresa pode indiretamente beneficiar-se economicamente, desde que a boa imagem contribua para o aumento das ações na Bolsa de Valores.

Para a captação de recurso, via patrocínio ou editais, é importante que uma ONG como o IEB apresente relatórios contábeis que comprovem saúde financeira e capacidade autossustentável. Para tanto, o fluxo de caixa representa uma ferramenta importante para a gestão contábil. Este se torna ainda mais eficiente na tomada de decisões quando associado a outros métodos quantitativos de análise econômica de projetos como valor presente líquido (VPL), payback e taxa interna de retorno (TIR) (CRESWELL, 2007).

No presente projeto, foram utilizados os indicadores de rentabilidade e de risco. Os de rentabilidade foram VPL e índice benefício/custo (IBC). Os de risco foram TIR, retorno sobre o investimento (ROI) e período de recuperação do investimento (payback).

O VPL representa o valor resultante das somas algébricas de fluxos de caixa futuros, descontada a taxa de juros compostos em uma determinada data, ou data zero (LAPPONI, 2007).

O IBC aponta quanto o projeto vai gerar por cada Real investido à taxa mínima de atratividade. Portanto, o IBC expressa a razão entre o fluxo de caixa esperado de benefícios pelo fluxo esperado de investimentos.

A TIR representa a maior rentabilidade que o projeto pode oferecer, enquanto o ROI expressa, exclusivamente, o retorno financeiro que a empresa obterá investindo no projeto. 0 payback, por outro lado, é o número de períodos necessários para recuperar o capital investido.

A TMA definida para o projeto é de $0,5 \%$ ao mês, o que representa um valor próximo à rentabilidade da caderneta de poupança. Esse valor foi definido pela equipe do IEB, considerando que o Instituto não objetiva lucro, mas sim sustentabilidade econômica.

Para o cálculo dos indicadores, foi utilizado o fluxo de caixa projetado para quatro anos de vida do projeto (Tabela 1).

Tabela 1 - Fluxo de caixa projetado do Projeto Ariranha

\begin{tabular}{|c|c|c|c|c|}
\hline & $\mathrm{R} \$ 59.700,00$ & $R \$ 93.300,00$ & $\mathrm{R} \$ 98.100,00$ & $\mathrm{R} \$ 108.950,00$ \\
\hline$-R \$ 288.410,39$ & $1^{\circ}$ ano & $2^{\circ}$ ano & $3^{\circ}$ ano & $4^{0}$ ano \\
\hline
\end{tabular}
Tabela 2.

Os valores dos indicadores de desempenho financeiro obtidos para o projeto podem ser observados na 
Tabela 2 - Indicadores financeiros obtidos (VPL, VPLa, IBC, TIR e ROI)

\begin{tabular}{c|c}
\hline Indicadores & Esperado \\
\hline Valor Presente Líquido (VPL) & $\mathrm{R} \$ 27.448,51$ \\
Valor Presente Líquido Anualizado (VPLa) & $\mathrm{R} \$ 7.740,80$ \\
Índice Benefício/Custo (IBC) & $\mathrm{R} \$ 1,0952$ \\
Taxa Interna de Retorno(TIR) & $8,6846 \%$ \\
Retorno sobre o Investimento (R0I) & $2,30 \%$ \\
\hline
\end{tabular}

Fonte: Os autores (2012)

O tempo necessário para o investidor recuperar o capital investido é apresentado na Tabela 3.

Tabela 3 - Tempo de recuperação do capital investido

\begin{tabular}{c|c|c}
\hline Período & Fluxo Caixa Descontado & PAYBACK \\
\hline 0 & 0 & \\
1 & $R \$ 57.129,1866$ & $\mathrm{R} \$ 57.129,19$ \\
2 & $\mathrm{R} \$ 85.437,6045$ & $\mathrm{R} \$ 142.566,79$ \\
3 & $\mathrm{R} \$ 85.964,6969$ & $\mathrm{R} \$ 228.531,49$ \\
4 & $\mathrm{R} \$ 91.361,2584$ & $\mathrm{R} \$ 319.892,75$ \\
\hline
\end{tabular}

Fonte: Os autores (2012)

Conforme os dados calculados, o VPL resultou em $\mathrm{R} \$ 27.448,51$, representando o ganho sobre o valor investido, acima da TMA de 5\%. O VPLa foi $\mathrm{R} \$ 7.740,80$ (valor anualizado, dividido em médias aproximadas) para o período de quatro anos. Esse valor demonstra os ganhos obtidos para cada ano do desenvolvimento do projeto. 0 resultado obtido com a VPL indica que o projeto deve ser considerado.

O IBC, de 1,0952, indica que, para cada $\mathrm{R} \$ 1,00$ imobilizado no projeto, o investidor retira 1,0952, a mais do que seria obtido se aplicado tendo como referência a TMA. Cabe ressaltar que essse valor é obtido ao final do horizonte de planejamento do projeto, que é de quatro anos. Isso equivale a um ganho de $9 \%$ sobre o capital investido, acima da TMA.

A TIR do projeto foi de $8,6846 \%$, significando a maior rentabilidade que o projeto pode obter no período considerado. Para uma TMA de 5\% a.a., o valor da TIR apresenta 3,6846 pontos acima, indicando, consequentemente, uma boa rentabilidade. O ROI ou taxa de lucro foi de $2,30 \%$, demonstrando o bom desempenho do investimento.

Considerando o conjunto dos dados calculados para o projeto, pode-se afirmar que o projeto é viável. 0 retorno do valor investido ocorre entre o terceiro e o quarto ano. Entretanto, deve-se levar em conta que este projeto possui um valor inicial alto de investimento, e o retorno encontra-se situado na etapa final do horizonte do projeto. Por outro lado, o desempenho financeiro do presente projeto deve ser abordado dentro de outra perspectiva, não somente do ponto de vista da lucratividade.

Para uma OSCIP como o IEB, a autossustentabilidade é o objetivo principal, já que uma ONG não tem fim econômico. Isso não significa que a organização não necessite ser viável economicamente. Para um patrocinador que investe numa ONG, é de suma importância que ela seja sustentável, ou melhor, que mesmo que o patrocínio cesse, a ONG continue funcionando. Isso garante a continuidade dos trabalhos e um retorno maior à empresa investidora cuja marca está associada a um projeto ativo. A análise da viabilidade econômico-financeira mostra-se uma ferramenta importante para comprovar a validade de um projeto e, com isso, contribuir para a captação de recursos.

A composição do projeto consistiu de várias etapas como: (1) Gerenciamento do projeto; (2) implantação da base de pesquisa; (3) Desenvolvimento da Pesquisa; (4) Mobilização Social; e (5) Relatórios. As tarefas do projeto foram relacionadas a essas entregas e apresentadas na forma de uma Estrutura Analítica do Projeto (EAP). 0 objetivo da referida estrutura é apresentar uma visão holística do projeto, facilitando a gestão pelo gerente do projeto, a execução pela equipe do projeto, assim como o acompanhamento pelas demais partes interessadas ou stakeholders. A EAP pode ser observada na Figura 4. A EAP detalhada para o gerente do projeto é apresentado na Figura 5. 
Figura 4 - EAP do Projeto Ariranha com as principais tarefas programadas

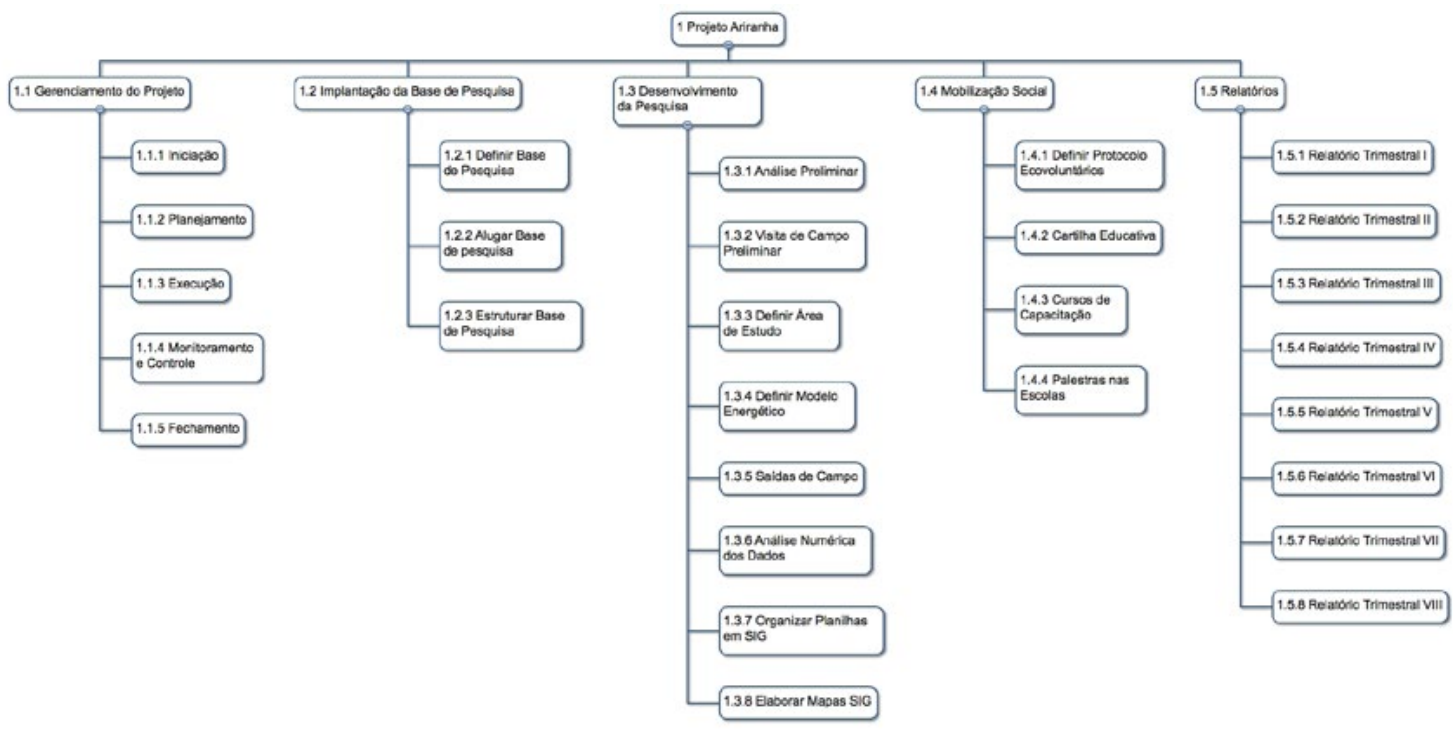

Fonte: Os autores (2012)

Figura 5 - Estrutura Analítica do Projeto detalhada para o gerente do projeto

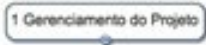
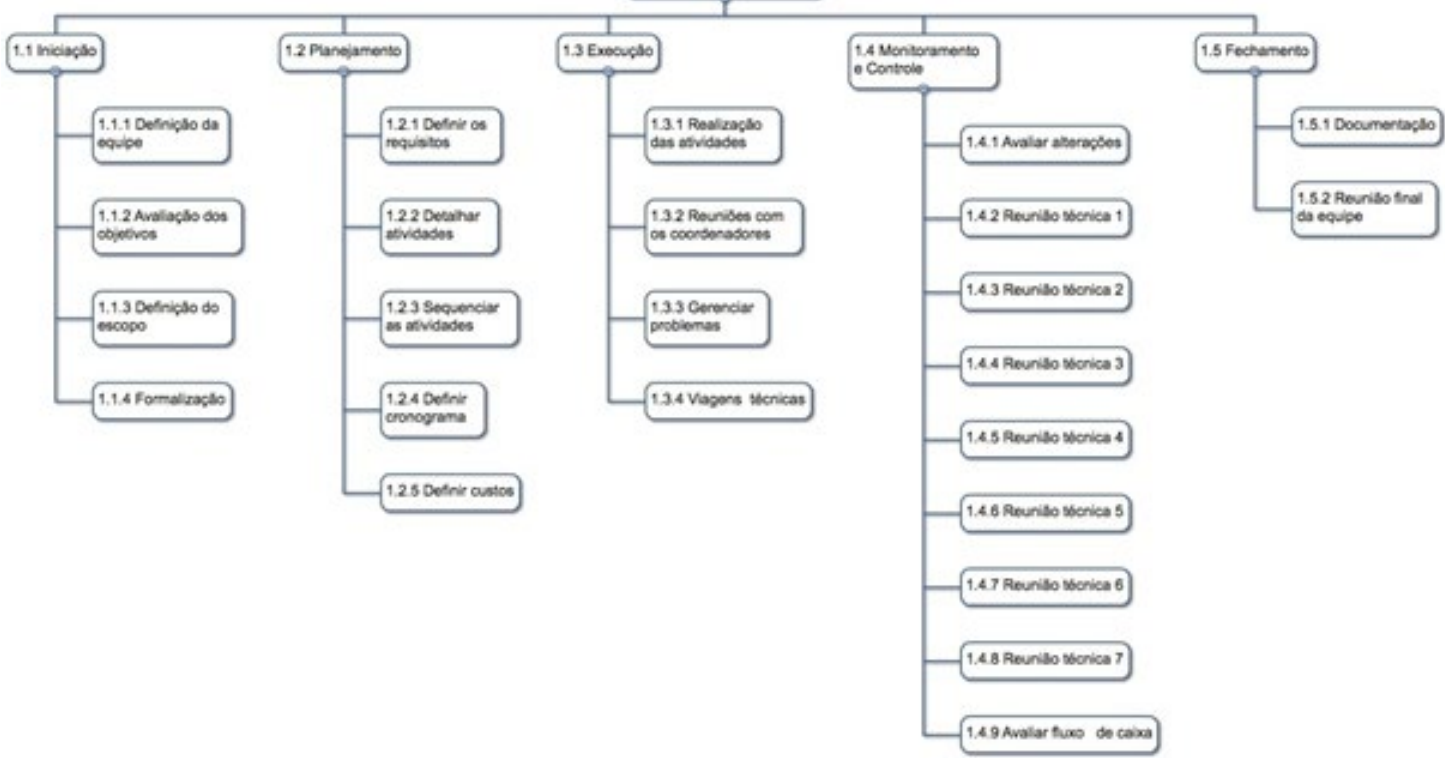

Fonte: Os autores (2012)

Foram definidos marcos de controle do projeto, os quais demandam o emprego de recursos financeiros e de recursos materiais, além da ação integrada da equipe e do gerente do projeto. A Tabela 4 exibe os principais marcos. 


\begin{tabular}{c|c}
\multicolumn{2}{c}{ Tabela 4 - Principais marcos de controle do projeto } \\
\hline Marco & Data \\
\hline Alugar a base de pesquisa & 18.02 .2013 \\
Elaborar mapas e banco de dados em SIG & 21.02 .2014 \\
Saída de Campo 1 & 08.04 .2013 \\
Saída de Campo 7 & 07.10 .2013 \\
Palestra na escola (Primeira) & 01.04 .2013 \\
Curso de Capacitação (Primeiro) & 03.03 .2014 \\
Cartilha educativa & 07.04 .2014 \\
Relatório Trimestral I & 17.03 .2013 \\
Relatório Trimestral II & 17.06 .2013 \\
Relatório Trimestral III & 17.09 .2013 \\
Relatório Trimestral IV & 17.12 .2013 \\
Relatório Trimestral V & 17.03 .2014 \\
Relatório Trimestral VI & 17.06 .2014 \\
Relatório Trimestral VII & 17.09 .2014 \\
Relatório Trimestral VIII & 17.12 .2014 \\
Reunião final da equipe & 20.12 .2014 \\
\hline
\end{tabular}

Fonte: Os autores (2012)

Foram definidos sete indicadores de desempenho e metas do projeto. Os indicadores são: relatórios trimestrais, relação receita/despesa, variação de custo (VC), variação do prazo (VPr), índice de desempenho de custo (IDC), índice de desempenho de prazo (IDPr) e variância no término (VNT). Os relatórios trimestrais são analisados conforme formulário padrão preenchido, incluindo ali os resultados obtidos e objetivos alcançados no período, em atendimento à matriz lógica do projeto.

Os objetivos do projeto são projetados para serem alcançados num prazo de dois anos, conforme escopo e cronograma previamente definido. Dentre os produtos previstos, o plano de gerenciamento do projeto foi, obviamente, o primeiro a ser finalizado. A Base de Pesquisa foi instalada com sucesso, no centro de Aquidauana, Rua Augusto Mascarenhas, no 309 (Figuras 6 e 7).

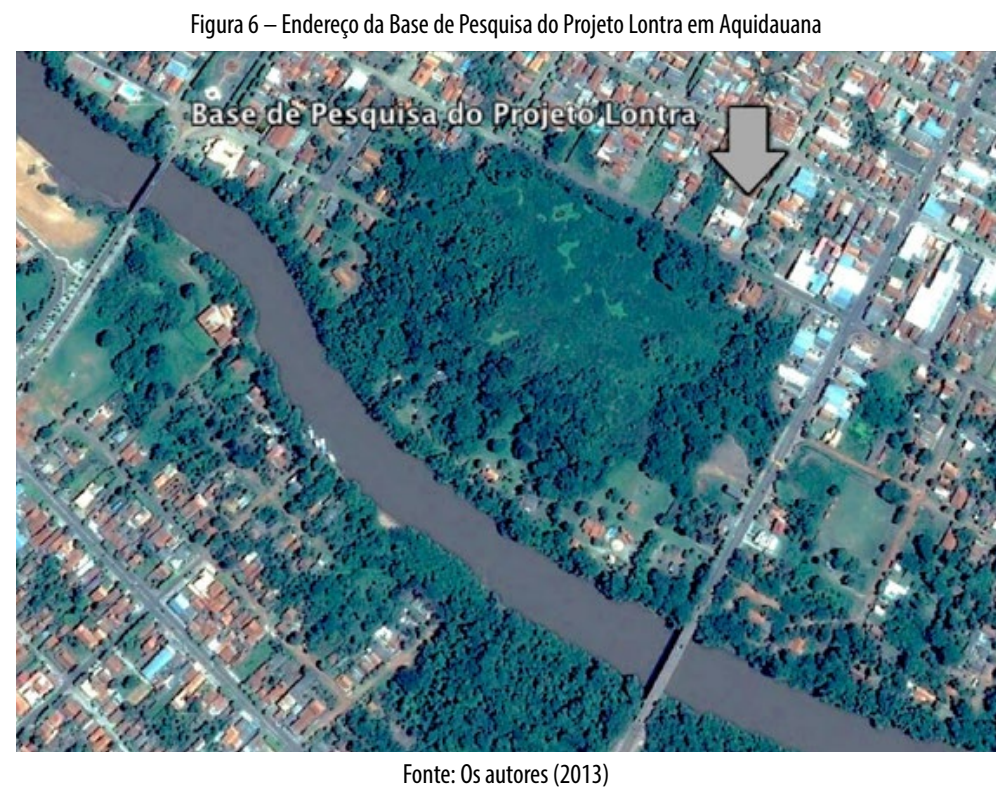




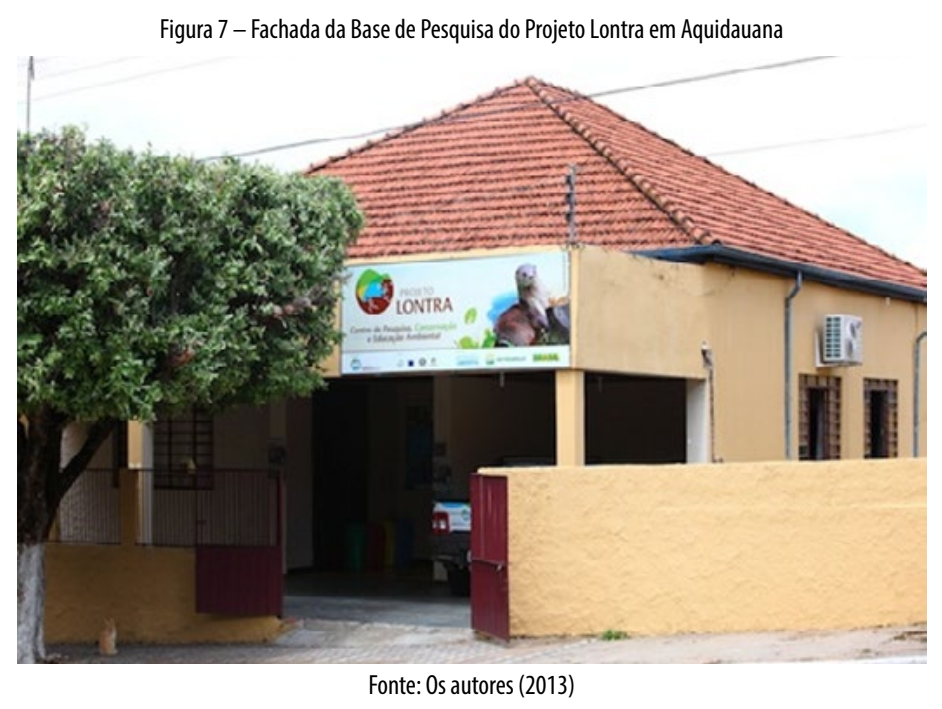

O banco de dados estruturado em SIG; mapas temáticos ambientais e socioeconômicos estão em desenvolvimento, iniciados pelo zoneamento do uso do solo numa faixa de 10 quilômetros ao longo de cada margem do rio Aquidauana. 0 rio Aquidauana possui cerca de 80 metros de largura. Portanto, a área inclui a Área de Preservação Permanente que, de acordo com a Lei no 12.651, de 25 de maio de 2012, é de 100 metros nas margens de rios entre 50 e 200 metros de largura (Figura 8). 0 produto final do zoneamento, juntamente com os mapas temáticos socioambientais estão previstos para o último trimestre de 2014.

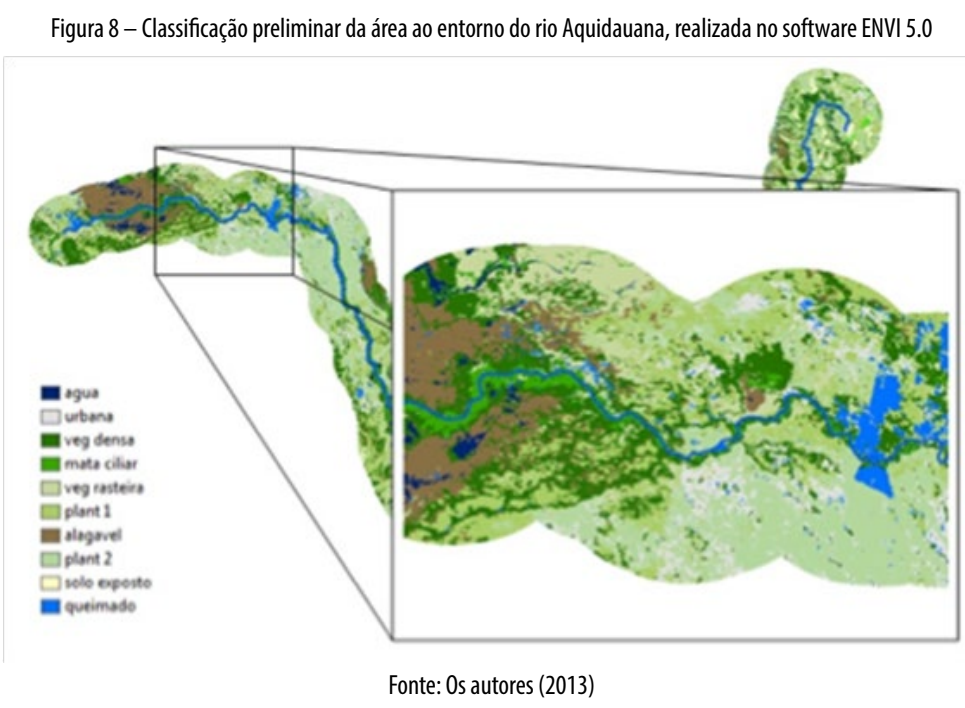

O curso de capacitação em turismo de conservação de base comunitária e a cartilha de educação ambiental estão em fase de finalização, com previsão de entrega para o primeiro e segundo trimestre de 2014, respectivamente. 0 curso de turismo de conservação já possui o plano de ensino e conteúdo programático definido, e será ministrado na base do projeto, em parceria com a Fundação de Turismo do Município e com o Curso de Turismo da Universidade Federal do Mato Grosso do Sul.

Em 2013, apenas em Aquidauana, foram atendidas 140 pessoas diretamente em ações de educação ambiental, sendo 43 professores e 566 crianças da rede pública municipal. Um total de 8.659 pessoas foram atingidas indiretamente pelas ações do projeto. 


\section{CONCLUSÃO}

0 trabalho tem como objetivo principal implementar um projeto de pesquisa autossustentável de conservação da ariranha no Pantanal do Mato Grosso do Sul, com base na pesquisa e no desenvolvimento do turismo de conservação de base comunitária com participação de ecovoluntários.

Para tanto, foi implementada uma base de operações com alojamento para pesquisadores e ecovoluntários no município de Aquidauana. A base serve de suporte para as várias atividades de mobilização social, educação ambiental e pesquisa desenvolvidas na região. Um banco de dados socioeconômico e ambiental em SIG da área de estudo está em desenvolvimento como apoio à continuidade do projeto. Foi criado um protocolo de atendimento para ecovoluntários, e um curso de turismo de conservação de base comunitária foi definido e ministrado a partir de março de 2014.

O Guia PMBOK® serviu como parâmetro para a formatação e o planejamento do projeto. A integração das áreas de gerenciamento facilitou para que o planejamento do projeto ficasse mais claro, objetivo, organizado e coerente. Ao final dos dois anos de implementação do projeto, espera-se que a conservação da biodiversidade seja beneficiada pela participação da comunidade local. A modificação da realidade, transformando a imagem da ariranha em algo positivo, deve ser alcançada mediante a participação dos ecovoluntários e do turismo de conservação, com o apoio da comunidade.

O tema transversal, no presente caso, busca trazer para o centro das discussões os aspectos éticos e morais que estarão por trás das ações de mobilização social. Apesar de toda a comunidade estar envolvida, o foco principal são as crianças e os professores, vistos como precursores e multiplicadores das ações e ideias. Dessa forma, as escolas do município são parte importante desse processo, palco importante para a discussão e reflexão da responsabilidade social de todos. Para tanto, todo o trabalho é enquadrado nos planos de gerenciamento do projeto: integração, escopo, tempo, custo, qualidade, recursos humanos, comunicações, riscos e aquisições.

Os benefícios econômicos, associados às pesquisas, questões éticas e morais deverão representar o sucesso do empreendimento, na forma de um projeto de conservação de base comunitária com participação de ecovoluntários brasileiros e estrangeiros. Cabe ressaltar a importância de um gestor de projetos que integre esforços, atuando com a equipe, o patrocinador, as agências de turismo responsáveis pelo envio de ecovoluntários, e com os formadores de opinião na comunidade. Fica claro que as habilidades e competências do gestor de projetos contam em grande parte para o sucesso do processo de elaboração, execução, monitoramento e resultados esperados do projeto.sucesso do empreendimento, na forma de um projeto de conservação de base comunitária com participação de ecovoluntários brasileiros e estrangeiros. Cabe ressaltar a importância de um gestor de projetos que integre esforços, atuando com a equipe, o patrocinador, as agências de turismo responsáveis pelo envio de ecovoluntários, e com os formadores de opinião na comunidade. Fica claro que as habilidades e competências do gestor de projetos contam em grande parte para o sucesso do processo de elaboração, execução, monitoramento e resultados esperados do projeto.

\section{GIANT OTTER PROJECT: APPLYING PROJECT MANAGEMENTTOTHE CONSERVATION OF BIODIVERSITY}

\section{ABSTRACT}

This article presents a research report of the first phase of the Giant Otter Project, which aims at the establishment of a research base in the Pantanal of Mato Grosso do Sul, the largest wetland area in Brazil, and to support the research and development of community-based conservation tourism having the giant otter (Pteronura brasiliensis) as a flagship species. The planning and execution of the project involves the application of the $\mathrm{PMBOK}^{\circledR}$ good practices. The methodology for the study of the ecology of the giant otter includes community engagement and participation of Brazilian and foreign ecovolunteers. The engagement of the local community is based on the appreciation of local and regional culture and the dissemination of regional products, as well as the motivation for the establishment of family hostels. The social mobilization and environmental education aim to create a community-based support for the project and thus create positive rapport with the target species. The study area for the project implementation is the Pantanal of Mato Grosso do Sul. Up to the moment, a GIS dataset of the land occupation which covers $10 \mathrm{~km}$, each side of the Aquidauana River, a course on Conservation Tourism and an environmental education book for children 
were produced. The results achieved by the end of the first phase of the project provided the basis for the implementation of the next phase destined to field research.

Keywords: : Project management. Tourism conservation. Community based. Social mobilization. Pteronura brasiliensis.

\section{Agradecimentos}

Este trabalho é patrocinado pela Petrobras, por meio do Programa Petrobras SócioAmbiental. Nós gostaríamos de agradecer ao Senac/Florianópolis e seus professores pelo apoio ao projeto e às valiosas sugestões. Também gostaríamos de agradecer aos revisores pelas correções e sugestões, o que valorizou ainda mais o trabalho.

\section{REFERÊNCIAS}

ARENDT, Hannah. A Condição Humana. São Paulo: Forense Universitária, 1981.

BENIZ, D. B.; ORIDES JÚNIOR, M.; KATO, Edilson R. R. Análise Preliminar do Uso do Open Project como Ferramenta de Gestão. In: Congresso de Iniciação Científica, 16., 2008, São Carlos. Anais de Eventos da UFSCar. São Carlos: UFSCar, 2008. p. 475.

BRASIL. Casa Civil. Lei no 9.790, de 23 de março de 1999. [1999]. Disponível em: <http://www.planalto. gov.br/ccivil_03/leis/19790.htm>. Acesso em: 29 maio 2014.

BRITO, Paulo. Análise e Viabilidade de projetos de Investimentos. 2. ed. São Paulo: Atlas, 2006.

CARTER, S. K.; ROSAS, F. C. W. Biology and Conservation of the Giant Otter Pteronura Brasiliensis. Mammal Review, Bristol, UK, v. 27, p. 1-26, 2007.

CARVALHO JUNIOR, O.; SPERB, Rafael Medeiros. A Bacia Catarinense do Rio Uruguai e o turismo de conservação como ferramenta ao desenvolvimento sustentável regional. Revista Brasileira de Ecoturismo, São Paulo, v. 5, n. 1, p. 67-86, 2012.

CARVALHO JUNIOR, O.; SCHMIDT, A.D. Ecotourism as a tool for the conservation of endangered species in the coastal region of Santa Catarina, Brazil. Journal of Coastal Research, Florida, n. 39, p. 959-961, 2004.

CARVALHO JUNIOR, O.; RODRIGUES, R.; SCOTON, G. Sistema de Informação Geográfico (SIG) como ferramenta auxiliar para o planejamento e gestão do turismo na Bacia Hidrográfica do Rio Itajaí (Santa Catarina). Caderno Virtual de Turismo, Rio de Janeiro, v. 9, n. 1, p. 63-87, 2009.

CHIARELLO, A. G. et al. Mamíferos ameaçados de extinção no Brasil. In: MACHADO, Angelo Barbosa Monteiro; DRUMMOND, Gláucia Moreira; PAGLIA, Adriano Pereira (Org.). Livro Vermelho da Fauna Brasileira Ameaçada de Extinção. Belo Horizonte: Fundação Biodiversitas, 2008. v. 2. p. 680-880.

COUGHLAN, P.; COGHLAN, D. Action research for operations management. International Journal of Operations and Production Management, Bingley, UK, v. 22, n. 2, p. 220-240, 2002.

CRAIGHEAD, C. W.; MEREDITH, J. Operations management research: evolution and alternative future paths. International Journal of Operations \& Production Management, Bingley, UK, v. 28, n. 8, p. 710726, 2008.

CRESWELL, John W. Projeto de pesquisa: método quantitativo, qualitativo e misto. 2. ed. Porto Alegre: Artmed, 2007. 
DOLABELA, Fernando. 0 segredo de Luísa. Rio de Janeiro: Sextante, 2008a.

DOLABELA, Fernando. Oficina do empreendedor. Rio de Janeiro: Sextante, 2008b.

DUPLAIX, Nicolle. Observations on the Ecology and Behavior of the Giant Tiver Otter Pteronura Brasiliensis in Suriname. Rev. Ecol. Terre Vie, v. 34, p. 496-620, 1980.

EISENBERG, J.F.; REDFORD, K.H. Mammals of the Neotropics: The Central Neotropics: Ecuador, Peru, Bolivia, Brazil. Chicago: The University of Chicago Press, 1999. v. 3.

EMMONS, L.H.; FEER, F. Neotropical Rainforest Mammals: a field guide. 2. ed. Chicago: University of Chicago Press, 1999.

GROENENDIJK, Jessica et al. Surveying and Monitoring Distribution and Population Trends of the Giant Otter (Pteronura Brasiliensis). Habitat, Hankensbüttel, v. 16, p. 1-500, 2005.

HOEFFEL, J. L. et al. Trajetórias do Jaguary - Unidades de Conservação, Percepção Ambiental e Turismo Um Estudo na APA do Sistema Cantareira. Ambiente e Sociedade, Campinas, v. 11, p. 131-148, 2008.

INSTITUTO BRASILEIRO DE GEOGRAFIA E ESTATÍSTICA PESQUISA (IBGE). De orçamentos familiares 2008-2009: Antropometria e Estado nutricional de crianças, adolescentes e adultos no Brasil. Rio de Janeiro: IBGE, 2010.

LAPPONI, Juan Carlos. Projetos de Investimentos na Empresa. Rio de Janeiro: Elsevier, 2007.

LEFF, E. Epistemologia Ambiental. 3. ed. São Paulo: Cortez, 2002.

MELLO, Carlos Henrique Pereira et al. Pesquisa-ação na engenharia de produção: proposta de estruturação para sua condução. Produção, v. 22, n. 1, p. 1-13, jan./fev. 2012.

MOURA, Dácio Guimarães; BARBOSA, Eduardo F. Trabalhando com projetos: Planejamento e gestão de projetos educacionais. Petrópolis: Vozes, 2006.

PEREIRA, C. R. Desenvolvimento de um programa de monitoramento em longo prazo das Ariranhas (Pteronura Brasiliensis) no Pantanal Brasileiro. 2004. Dissertação (Mestrado) - Universidade Federal do Mato Grosso do Sul, Campo Grande.

PROGRAMA DAS NAÇÕES UNIDAS PARA O DESENVOLVIMENTO (PNUD). Atlas de Desenvolvimento Humano 2011. [2011]. Disponível em: <http://www.pnud.org.br/atlas/>. Acesso em: 11 jun. 2014.

REIS, N. R. et al. Mamíferos do Brasil. Londrina: [s.n.], 2006.

THIOLLENT, M. Metodologia da pesquisa-ação. 15. ed. São Paulo: Cortez, 2007.

TOMÁS, Walfrido et al. Potencial dos Rios Aquidauana e Miranda, no Pantanal de Mato Grosso do Sul, para a conservação da Ariranha (Pteronura Brasiliensis). In: Simpósio sobre recursos naturais e sócioeconômicos do Pantanal: Os desafios do Novo Milênio, 3., 2000, Corumbá. Anais do III Simpósio sobre Recursos Naturais e Sócio-econômicos do Pantanal. Corumbá: EMBRAPA PANTANAL, 2000. p. 1-12.

TORO, Jose Bernardo; WERNECK, Nisia Maria Duarte. Mobilização Social: um modo de construir a cidadania e a participação. Belo Horizonte: Autêntica, 2004. 